DEPARTMENT OF ECONOMICS

Price competition between subsidized organizations Jan Bouckaert \& Bruno De Borger

\author{
UNI VERSITY OF ANTWERP \\ Faculty of Applied Economics \\ Stadscampus \\ Prinsstraat 13, B. 213 \\ BE-2000 Antwerpen \\ Tel. +32 (0)3 2654032 \\ Fax +32 (0)3 2654799 \\ http://www.ua.ac.be/tew
}




\section{FACULTY OF APPLIED ECONOMI CS}

\section{DEPARTMENT OF ECONOMICS \\ Price competition between subsidized organizations}

Jan Bouckaert \& Bruno De Borger

RESEARCH PAPER 2010-019

AUGUST 2010
University of Antwerp, City Campus, Prinsstraat 13, B-2000 Antwerp, Belgium Research Administration - room B. 213 phone: (32) 32654032 fax: (32) 32654799
e-mail: joeri.nys@ua.ac.be

The papers can be also found at our website: www.ua.ac.be/ tew (research > working papers) \& www.repec.org/ (Research papers in economics - REPEC)

D/ 2010/ 1169/019 


\title{
Price competition between subsidized organizations
}

\author{
Jan Bouckaert and Bruno De Borger*
}

August 25, 2010

\begin{abstract}
Many firms and organizations compete for customers while at the same time receiving substantial funding from outside sources, such as government subsidies. In this paper, we study the effects of two commonly observed, alternative subsidy systems on the behavior of price-competing firms. Specifically, we compare an open-ended per-unit price subsidy with a closed-ended subsidy, allocated according to the firms' market shares. We find that, holding the total subsidy budget constant, the open-ended subsidy results in fiercer price competition, lower prices, higher output, and lower profits than the closed-ended, market-share based alternative. Second, the open system yields higher overall welfare for relatively modest subsidies and limited substitutability between goods; the closed system performs better at relatively high subsidy levels and when goods are closer substitutes. Third, a market-share based subsidy makes collusive behavior between firms much harder. Our results, therefore, suggest a potential trade-off between short-run and long-run objectives: subsidies designed to widen participation may stimulate collusive behavior. These findings may have important policy implications for the design of subsidy systems in, among many others, education and the arts.
\end{abstract}

JEL codes: D43, H52, I28, L13.

Keywords: subsidy allocation rules, Bertrand competition, incentives to collude

*Department of Economics, University of Antwerp. Prinsstraat 13, B-2000 Antwerp, Belgium (jan.bouckaert@ua.ac.be; bruno.deborger@ua.ac.be). Financial support from the Interuniversity Attraction Pole (IAP P6/09) and the University of Antwerp’s TOP-program are gratefully acknowledged. We thank Brett Graham, Patrick Legros, Wilfried Pauwels, Johan Stennek, Frank Verboven, and seminar participants at the universities of Antwerp, Gothenburg and Xiamen for helpful comments 


\section{Introduction}

The revenues of many firms and organizations do not only stem from the prices they charge to their customers. In some instances, other sources of income may represent a considerable fraction of their revenues. For example, theatres, operas, museums, and other artistic organizations compete for audience while receiving significant subsidies from diverse governmental agencies and sponsoring firms. ${ }^{1}$ In most countries, universities and other institutes of higher education directly compete for students, but at the same time they benefit from considerable government funding. ${ }^{2}$ In some industrial sectors, firms fight for customers while receiving government subsidies for making use of environmentally-friendly production techniques (Fischer, 2003). Of course, outside sources are not limited to government subsidies. For example, it is not unusual for sports leagues to allocate funds from a common revenue source, like broadcasting rights, among their league members (see e.g. Szymanski (2003)).

A government may have a variety of reasons for granting subsidies. It may (i) subsidize artistically related activities to prevent their local cultural heritage from disappearing; (ii) provide subsidies when they have a social concern about the output level of a monopolistic firm (Segal (1998)); (iii) subsidize institutes of higher education to support economic growth or, for distributional reasons and to limit social exclusion, to further expand participation rates; (iv) grant subsidies to cope with negative externalities. For example, it may subsidize cleanproducing firms in order to promote the use of renewable energy sources. Finally, private organizations may have specific incentives to provide funding as well. Sports leagues redistribute common broadcasting revenues among their league members, subsidizing the weaker league members at the cost of the stronger teams, to preserve the degree of competitive balance between the different competing teams.

In this paper, we study the effects of different allocation rules for subsidizing, or distributing funds to, competing organizations. Although they can take many forms, a

\footnotetext{
${ }^{1}$ For example, the revenues in 2009 of the Royal Opera House in London amounted to 90 million pounds, of which 40 million pounds came from ticket sales and 27 million pounds from government funds. The remaining part came from individual funds and other commercial activities (Forbes.com, September 19, 2009). See also Van Der Ploeg (2005) for an overview of cultural expenditures in European countries.

${ }^{2}$ Government subsidies to public institutes of higher education are considerable. Heckman (2000) estimates for the US that, on average, students attending public institutes of higher education pay less than $20 \%$ of the total cost of education. See e.g. Winston (1999), Barr (2004) and Santiago et al. (2008)) for surveys on the economics of higher education funding.
} 
behaviorally relevant distinction is that between open-ended and closed-ended systems ${ }^{3}$. Typical examples of open-ended funding are a fixed government subsidy per unit (per spectator, per product sold, per enrolled student, etc.) or an ad valorem price subsidy. Obviously, open systems imply that the total cost to the sponsoring organization depends on demand responses (e.g., ownand cross-price elasticities) to induced price changes. Alternatively, closed-ended funding systems imply that a fixed total budget is available for distribution across firms in the industry. In the case of government subsidies, the total budget is typically fixed and decided upon ex ante through the political process. In other instances, such as sports leagues, the budget is the result of a sector-specific process (for example, overall broadcasting rights negotiated by the league or, individually, by every league member). In both cases, the available budget is then distributed across firms according to a predetermined allocation mechanism; for example, subsidies could be granted according to firms’ market share in total sector output.

While real-world subsidies typically involve complex allocation rules, examples of subsidies that are broadly consistent with one of the systems just described are frequently observed in practice. Examples of open-ended production subsidies are observed in international trade (see e.g. Collie (2000)), the cultural sector (Van Der Ploeg, 2005), and in education. A prominent education example is Denmark's “taximeter” model, in which universities get funding per passing student (see Kalpazidou et al. (2007)). Examples of closed-ended systems in which allocation is based on market-shares can be found in education (for example, the funding of universities in Belgium), environmental economics (the redistribution of the revenues from emission taxes among polluters in Sweden, the system of output-based refunding of environmental taxes in the US (Fischer (2003)), and in international trade (Krishna et al. (2001)). Finally, closed-ended subsidies other than those based on market shares have been observed, for example, in models of entrepreneurial investment (Fuest and Tillessen (2005)).

The purpose of this paper is to compare the effects of closed and open-ended funding systems on price-competing organizations. For purposes of concreteness, we will frame the model in terms of different types of government subsidies; however, the analysis is more

\footnotetext{
${ }^{3}$ Subsidies can be granted as a lump sum, or they can be linked to particular criteria like input use (e.g. size of the orchestra, maintenance cost of existing infrastructure, ...), outputs (e.g. consumption units, attendance at a theatre performance, number of hospital patients or passing students...), market share, etc. Our focus in this paper is on comparing a per-unit open-ended system with market-share based closed-ended system. Lump-sum subsidies or subsidies based on use of specific inputs are not considered. Note that there are also numerous implicit ways of granting subsidies through favorable tax regimes, such as tax breaks for revenues, R\&D investments, or private donations.
} 
generally applicable to other settings where funds are allocated to competing organizations according to particular allocation rules. We analyze a stylized model with two price-competing firms offering a differentiated product, and consider the effects of two subsidy systems: in the open system, the government provides a per unit subsidy that is known by firms ex ante; the alternative closed system assumes that a fixed subsidy is available for the sector as a whole, and that the allocation rule is based on firms' market shares in industry output. We focus on two important but specific issues. First, we analyze the effects of both subsidy systems for prices, output, profits, and welfare. Second, we study the implications of different types of subsidies for the long-run incentives to collude.

The findings of this paper are the following. First, we show that the open system is more efficient in the sense of Anderson et al. (2001a, b): holding the total subsidy budget constant, a per-unit subsidy results in fiercer price competition than a market-share based subsidy. As a result, it generates a larger market output and therefore is more effective at stimulating participation. Put differently, firms enjoy larger profits under the closed system. Second, a formal welfare comparison yields ambiguous results in general: the open system performs better for relatively modest subsidies and low substitutability between goods, the closed system generates higher welfare at high subsidy levels and when goods are closer substitutes. Third, we find that variations in a per-unit subsidy have no effect on the incentives to collude. However, increasing the budget available for a market-share based subsidy increases the incentives to collude. We show that this implies there is less potential for collusion in a closed system. Interestingly, our results therefore imply that a trade-off between short-run and long-run objectives may exist in the sense that a closed system performs worse at stimulating participation, but at the benefit of lower incentives to collude.

To the best of our knowledge, a formal comparison of the effects of per-unit and marketshare based subsidy systems is not available in the literature. First, a number of papers have explicitly focused on open-ended price subsidies. For example, in an early paper Hansmann (1981) studied the implications of subsidies for the behavior of artistic organizations (museums, theatres, etc.) under various different objective functions. He considers different types of subsidies (lump sum and various open-ended subsidies like a per-unit price subsidy or a matching subsidy per dollar of revenues raised through donations) and analyzes the effects on ticket prices, output and welfare. More recently, Collie (2000) studies the competition between 
firms of different member countries of the European Union, when each country provides an open-ended optimal production subsidy (optimal in the sense of maximizing domestic welfare) to the local firm. He shows that each country indeed has an incentive to provide such subsidies, and that from a European Union viewpoint such subsidies are undesirable. Fethke $(2005,2006)$ offers a theoretical framework of competitive behavior in the subsidized market for public higher education; his focus is on a per unit enrollment subsidy. Finally, the most detailed study of the implications of open-ended taxes and subsidies in a differentiated oligopoly is probably Anderson, de Palma and Kreider (2001a, b). They specifically study the relative efficiency of ad valorem and per-unit taxes, defining the relative efficiency of the two tax systems according to whether a system yields higher tax revenues (lower subsidy costs) for given outputs or, alternatively, higher output for given tax revenue (subsidy costs). They show, among others, that ad valorem taxes are (both for Cournot and Bertrand competition) welfare superior to unit taxes if production costs are identical across firms; cost asymmetries make the case for ad valorem stronger under Cournot, but under Bertrand the opposite may hold. Although the current paper also deals with alternative forms of subsidies, it differs from Anderson et al. (2001a, b) on several accounts. We compare open with closed subsidy systems, whereas they study two variants of an open system. Moreover, we study both the welfare effects and the implications of different subsidy systems for the incentive to collude.

Second, several recent papers have focused on market-share based closed-ended subsidy schemes. For example, Krishna, Roy and Thursby (2001) study market access requirements (MAR), whereby an importing country voluntarily agrees a minimum share of its home market for a good from a foreign country. They look at a subsidy scheme where each targeted firm gets a subsidy proportional to its individual share of the market, provided the market access requirement is met at the aggregate level. ${ }^{4}$ Output-based refunding of environmental taxes in imperfectly competitive markets is another example of this type of closed-ended subsidy (see, e.g., Fisher (2003)). Under this system, producers are taxed according to their emissions, and total revenues are refunded based on the firm's market share in total output.

\footnotetext{
${ }^{4}$ The model assumes that, in the first stage of the game, the government announces that each targeted firm will receive part of a total subsidy equal to its individual market share, provided the aggregate US share meets the minimum level specified by the MAR. Referring to Sen (1966), the authors argue that share-based subsidies are more high-powered than specific subsidies, because they imply an externality: when one firm gets more, the other necessarily gets less.
} 
Third, at least one study has formally compared a closed-ended with an open-ended subsidy. Fuest and Tillessen (2005) focus on subsidies to support entrepreneurial investment. However, the closed system they consider is of a totally different nature than the market-share based system studied in this paper. They study a subsidy that is limited to a maximum amount and compare it with an open system that affects investment decisions at the margin. They show that, contrary to expectations, the closed system is welfare superior when capital markets are subject to asymmetric information.

A formal comparison of the effects of per-unit and market-share based subsidy systems may be important for several reasons. One is that subsidy systems widely differ across countries, even within the same sector: as noted above, the Danish system of education finance comes closest to an open subsidy, whereas other countries have opted for what is better described as a closed system, or a complex mixture of the two. Moreover, recent policy changes in some countries could be interpreted as a shift away from one system in the direction of the other. It is then useful to understand the effects of such policy changes ${ }^{5}$. Another justification for the analysis of the current paper is that very little is known about the long-run effects of different financing arrangements on the structure of the industry. To the extent that different subsidy systems have different implications for the incentives to collude, ways of funding that hamper long-run competition may be less desirable, independent of their effects on pricing and output in the short-run.

Although our model convincingly illustrates that different subsidy schemes may significantly alter the strategic behavior between organizations, it is highly stylized and simplifies many of the complexities of existing subsidy schemes. For example, we focus on price competition between profit- or revenue-maximizing organizations. This assumption may not be suited for all subsidized organizations we observe. Hansmann (1981) has argued that many artistic companies (theatres, etc.) probably do not care too much about profit; instead, they may care about quality, attendance, revenues, etc. Similarly, the appropriate objective function for institutes of higher education is likely to be highly multi-dimensional (see, e.g., Winston

\footnotetext{
${ }^{5}$ Belgium recently moved from a system with substantial open-ended funding to a more closed-ended system in financing its universities. They now receive part of the closed-ended funding according to their market share in the number of (entering or passing) students, publications, and citations. Also, see Barr (2004) for the recent reform in the UK.
} 
(1999)). ${ }^{6}$ We do think that profit or revenue maximizing behavior by the relevant firms or organizations may serve as a useful benchmark. Price competition in the US higher education market has increased significantly (see Winston and Zimmerman (2000)); moreover, the further globalization of education is likely to result into more tuition competition between European universities. Similarly, although large sports teams no doubt are also interested in winning games and drawing large audiences, their entry on the stock market in the UK and France, among others, suggests that profit maximization will become the rule rather than the exception, be it within the limits set by the league. We therefore believe that our model does capture important ingredients of a broad range of subsidy systems.

The structure of the paper is as follows. In Section 2, we present the structure of the model and explain the properties of the open and closed subsidy systems. Section 3 derives the market outcomes under Bertrand competition for each of the two subsidy systems. Section 4 reports on a detailed welfare analysis of the two subsidy systems. In Section 5 we consider the implications of the two types of subsidies for the incentive to collude on the output market. We summarize our conclusions in Section 6.

\section{The model}

There is a continuum of identical consumers who care about three goods. Preferences are assumed to be quasi-linear in the numéraire good -- so that we can ignore income effects -- and quadratic in the two other goods. In particular, we define a consumer's utility by ${ }^{7}$

$$
u\left(q_{1}, q_{2}, q_{0}\right)=q_{1}+q_{2}-0.5\left[q_{1}^{2}+2 d q_{1} q_{2}+q_{2}^{2}\right]+q_{0} .
$$

In this specification, $q_{0}$ denotes the quantity of the composite numéraire good, and $q_{1}$ and $q_{2}$ are the quantities of goods 1 and 2, respectively. Consumers have a budget constraint $y=q_{0}+p_{1} q_{1}+p_{2} q_{2}$, where $p_{1}$ and $p_{2}$ are the unit prices of goods 1 and 2 , respectively. We further assume that $0 \leq d<1$, so that consumers consider goods 1 and 2 as imperfect substitutes in consumption: the marginal utility of one good declines with more consumption of the other. The goods are independent when $d=0$, and become more substitutable when $d$ augments.

\footnotetext{
${ }^{6}$ Fethke (2005) assumes that universities maximize profit together with a weighted consumer welfare part.

${ }^{7}$ See Vives (1985) and Singh and Vives (1984) for a more general specification. For the purposes of our analysis, this simpler specification has the advantage of keeping the analysis tractable while at the same time preserving the main qualitative insights.
} 
The first-order conditions directly result in the consumer's inverse demand functions

$$
\begin{aligned}
& p_{1}\left(q_{1}, q_{2}\right)=1-q_{1}-d q_{2} \\
& p_{2}\left(q_{1}, q_{2}\right)=1-q_{2}-d q_{1} .
\end{aligned}
$$

By inversion, the demand system is readily obtained as

$$
\begin{aligned}
& q_{1}\left(p_{1}, p_{2}\right)=\frac{1}{1-d^{2}}\left[(1-d)-p_{1}+d p_{2}\right] \\
& q_{2}\left(p_{1}, p_{2}\right)=\frac{1}{1-d^{2}}\left[(1-d)-p_{2}+d p_{1}\right]
\end{aligned}
$$

as long as quantities demanded for both commodities remain positive. ${ }^{8}$ Note that our assumption on the parameter $d$ implies positive and symmetric cross-price effects between both goods. One easily shows, using (2), that higher values of $d$ yields larger cross-price effects.

We consider a duopolistic industry where one firm offers good 1 and the other firm sells good 2. Let each firm $i$ maximize its profits, with $i=1,2$. Assume zero production costs to simplify the analysis. Firms receive revenues from two sources. First, they charge a price $p_{i}$ (admission fee, ticket price, etc.) for their goods or services; second, they receive a government subsidy. As a result, profit of firm $i$ is given by

$$
\pi_{i}=p_{i} q_{i}+S_{i},
$$

where $S_{i}$ denotes the subsidy firm $i$ receives.

We study two subsidy systems. First, under an “open-ended” system, the sponsoring organization (the government, say) provides an ex ante announced subsidy $\gamma$ per unit of output. The subsidy received by firm $i$ then equals

$$
S_{i}=\gamma q_{i} .
$$

Second, under the "closed-ended" system, we assume that the sponsoring organization has a given fixed amount $\beta$ available for funding the industry. The available budget has been determined ex ante by, for example, an exogenous political or budgetary process. In our set-up,

\footnotetext{
${ }^{8}$ When firm $j$ charges too high a price, firm $i$ 's demand shows a kink at some critical price of firm $j$ for which $i$ has a monopoly position (see Deneckere (1983) and Singh and Vives (1984) for a complete characterization). In this paper, we do not consider firm $i$ 's incentives to exclude firm $j$ and become a monopolist when subsidies are available.
} 
the firms in the sector receive a fraction of $\beta$ according to their respective market shares. Accordingly, firm $i$ receives a subsidy of

$$
S_{i}=\beta \frac{q_{i}}{q_{1}+q_{2}} .
$$

\section{Bertrand competition between subsidized firms: prices, output, and profits}

\subsection{Bertrand competition with open-ended funding}

When the government provides a producer subsidy $\gamma$ per unit, each firm maximizes its profit by

$$
\max _{p_{i}} \pi_{i}=\max _{p_{i}}\left(p_{i}+\gamma\right) q_{i} .
$$

Using (1), the resulting necessary and sufficient first-order condition is given by

$$
1-d-p_{i}+d p_{j}=\left(p_{i}+\gamma\right) \text {. }
$$

Firm $i$ ' reaction function can be written as

$$
\begin{array}{ll}
p_{i}^{o}=0.5\left(1-d-\gamma+d p_{j}\right) & \text { if } 0 \leq p_{j}<\bar{p}_{j}^{o} \\
p_{i}^{o}=0.5(1-\gamma) & \text { if } p_{j}>\bar{p}_{j}^{o}
\end{array}
$$

where the superscript ' $O$ ' refers to the open-ended funding system and $\bar{p}_{j}^{o}$ is the cutoff price of firm $j$ that results in firm $i$ becoming a monopoly. Since we focus in what follows only on the case where both firms serve a positive share of the market, we assume throughout that $0 \leq p_{j}<\bar{p}_{j}^{o}$.

Reaction functions are upward sloping so that prices are strategic complements. Moreover, a higher degree of substitutability (a larger $d$ ) increases the slope and decreases the intercept of each firm's reaction curve. The total effect of increased substitutability is that firms optimally reduce their price for any given price set by their competitor. The slope of the reaction functions

$$
\frac{\partial p_{i}^{o}}{\partial p_{j}}=\frac{d}{2}
$$

lies between zero and one half, so that a stable Nash equilibrium is guaranteed. Solving the two reaction functions for prices, the (symmetric) Nash equilibrium looks like 


$$
p_{i}^{o^{*}}=p_{j}^{o^{*}}=\frac{1-\gamma-d}{2-d}
$$

In what follows, we limit the analysis to non-negative prices. That is, we focus only on values for $d$ and $\gamma$ such that (8) remains non-negative. ${ }^{9}$

When goods are independent $(d=0)$ and there are no subsidies $(\gamma=0)$, each firm charges the monopoly price of 0.5. Expression (8) further shows that equilibrium prices decrease when goods become better substitutes (higher $d$ ) or a higher subsidy $\gamma$ is provided. Finally, note that

$$
\frac{\partial^{2} p_{i}^{o}}{\partial \gamma \partial d}=-\frac{1}{(2-d)^{2}}<0 .
$$

Since the subsidy reduces prices, it follows that the impact of the subsidy rises when goods become better substitutes.

Using (2) and (8), each firm’s equilibrium quantity with open-ended funding equals

$$
q_{i}^{o^{*}}=q_{j}^{o^{*}}=\frac{1+\gamma}{(1+d)(2-d)}
$$

Firms sell more when the subsidy per unit augments. The impact of higher substitution between goods (a higher $d$ ) is ambiguous in general. Increasing $d$ reduces output for relatively modest substitutes $(d<0.5)$, it raises output for good substitutes $(d>0.5){ }^{10}$

Finally, using (8) and (9) we find that profit amounts to

$$
\pi_{i}^{o^{*}}=\pi_{j}^{o^{*}}=\frac{(1-d)(1+\gamma)^{2}}{(1+d)(2-d)^{2}} .
$$

Obviously, it increases with the size of the per-unit subsidy.

\subsection{Bertrand competition with closed-ended market-share based funding}

In the closed-ended subsidy system we consider, the sponsoring organization (e.g., the government) fixes its total subsidy budget $\beta$ beforehand. Each firm competes for scarce

\footnotetext{
${ }^{9}$ One could argue that in extreme cases subsidies may be so large that prices become negative. However, we believe that negative prices are not realistic for the industry examples that we have discussed in the Introduction.

${ }^{10}$ Two things happen when $d$ rises. On the one hand, it follows from (8) that increasing $d$ reduces equilibrium prices, but less so at high values of $d$; on the other hand, demand system (2) implies that it also makes demand more elastic. Combination of these two effects implies that the overall impact on demand is ambiguous a priori.
} 
resources and receives a fraction of the total budget according to the allocation rule of the tournament. Here we focus on one commonly observed rule in which each firm receives a fraction of the budget according to its market share. ${ }^{11}$ The problem for firm $i$ is then to

$$
\max _{p_{i}} \pi_{i}=p_{i} q_{i}+\beta\left[\frac{q_{i}}{q_{i}+q_{j}}\right] .
$$

The first-order condition can be written as, using (2):

$$
1-d-2 p_{i}+d p_{j}-\beta \frac{q_{j}+d q_{i}}{\left(q_{i}+q_{j}\right)^{2}}=0 .
$$

Substituting the demand functions (2) in (11), this expression implicitly defines the reaction function $p_{i}^{c}\left(p_{j} ; \beta, d\right)$ for any price $p_{j} \in\left[0, \bar{p}_{j}^{c}\right]$ set by firm $j$, where the superscript $c$ refers to the closed-ended funding system. As before, we focus on equilibrium outcomes where both firms serve a positive market share, since any price equal or larger than $\bar{p}_{j}^{c}$ is the price of $j$ that makes $i$ a monopoly. The second-order condition for a maximum is satisfied when

$$
-\beta(1-d)\left(q_{j}+d q_{i}\right)<\left(q_{i}+q_{j}\right)^{3} .
$$

This inequality holds whenever $d<1$, as we assumed.

From the first-order condition (11), we derive the slope of the reaction function as:

$$
\frac{\partial p_{i}^{c}}{\partial p_{j}}=\frac{d\left(q_{i}+q_{j}\right)^{3}}{2\left(q_{i}+q_{j}\right)^{3}+2 \beta(1-d)\left(q_{j}+d q_{i}\right)}>0 .
$$

Therefore, as in the case of the open-ended subsidy system, the reaction functions are upward sloping. Again, as $d<1$, the slope is less than one, which guarantees a stable Nash equilibrium.

Interestingly, comparing (7) and (12), we see that a market-share based closed-ended subsidy system implies less responsive reactions of firms to price changes by the competitor than a per-unit open-ended subsidy system. Since $d<1$, the slope of the reaction function in (12) is necessarily less than $0.5 d$, the slope under the per-unit subsidy derived in (7). The intuition for this difference in price-responsiveness is that, under the closed-ended system, a price increase by one firm imposes a positive externality on the competitor. To see this, we easily obtain, using (2), that

\footnotetext{
${ }^{11}$ European soccer leagues, e.g., share part of their pre-determined broadcast revenues according to league position or TV appearances. Universities in Belgium receive part of the closed-ended funding according to their market share in the number of (entering or passing) students, publications, and citations. Of course, other allocation rules could be used.
} 


$$
\frac{\partial\left(\frac{\beta}{\left(q_{i}+q_{j}\right)}\right)}{\partial p_{i}}=\frac{\beta}{(1+d)\left(q_{i}+q_{j}\right)^{2}}>0 .
$$

This positive effect of a price increase on the resulting subsidy expressed per unit, raises each firm's incentive to increase its own price. By doing so, it sells less but at the same time raises the subsidy it receives per unit of demand. More importantly, however, a price increase by one firm raises the subsidy per unit for the competitor, ceteris paribus. ${ }^{12}$ This windfall revenue gain induces a less pronounced reaction of firm $j$ to the price increase by firm $i$. Note, by contrast, that a price increase under the open-ended per-unit subsidy system does not affect the level of the unit subsidy $\gamma \cdot{ }^{13}$

Not surprisingly, using (11) we further find that raising $\beta$, the total budget available for subsidies, shifts the reaction functions inwards, or

$$
\frac{\partial p_{i}^{c}}{\partial \beta}=-\frac{\left(q_{j}+d q_{i}\right)}{2\left(q_{i}+q_{j}\right)^{2}}<0
$$

For any price charged by firm $j$, firm $i$ optimally charges a lower price to benefit from the increased government budget.

Note that the demand structure of our model implies a symmetric equilibrium with $q_{i}=q_{j}$. In any symmetric Nash equilibrium, $p_{i}^{c^{*}}=p_{j}^{c^{*}}=p^{c^{*}}$, so that, after substitution in (1), we find that

$$
\begin{aligned}
& (1+d) q=\left(1-p^{c}\right) \\
& 2 q=2\left(1-p^{c}\right) /(1+d) .
\end{aligned}
$$

Substituting these results in the first-order condition as expressed in (11), the latter can be written as

\footnotetext{
${ }^{12}$ In fact, starting from symmetric market shares, one can show that a firm's unilateral price increase actually raises the total subsidy received by the competitor.

${ }^{13}$ Of course, in either funding system a price increase by firm $i$ reduces both its market share and total demand.

Formally, we have that $\frac{\partial\left(q_{i}+q_{j}\right)}{\partial p_{i}}<0$ and $\frac{\partial\left(\frac{q_{i}}{\left(q_{i}+q_{j}\right)}\right)}{\partial p_{i}}<0$.
} 


$$
1-d-(2-d) p-\beta \frac{(1+d)^{2}}{4(1-p)}=0 .
$$

Solving for $p$ and choosing the only economically sensible root (the other root yields negative demand).yields the symmetric Nash equilibrium prices

$$
p_{i}^{c^{*}}=p_{j}^{c^{*}}=\frac{(3-2 d)-\sqrt{1+\beta(1+d) Z}}{2(2-d)}
$$

where $Z \equiv(2-d)(1+d)$. Profit-maximizing quantities per firm are given by

$$
q_{i}^{c^{*}}=\frac{1+\sqrt{1+\beta(1+d) Z}}{2 Z} .
$$

Each firm’s equilibrium profit equals

$$
\pi_{i}^{c^{*}}=p_{i}^{c^{*}} q_{i}^{c^{*}}+0.5 \beta
$$

From equations (14) and (15), the profits for the closed-ended subsidy system can be expressed as

$$
\pi_{i}^{c^{*}}=\pi_{j}^{c^{*}}=0.5 \beta+\frac{2(1-d)[1+\sqrt{1+\beta(1+d) Z}]-\beta(1+d) Z}{4(2-d) Z}
$$

Simple differentiation shows that an increase in the overall subsidy $\beta$ raises firms' profits.

\section{Open-ended versus closed-ended funding: comparing efficiency and welfare}

We noted above that a market share based closed-ended funding system implies (i) a lower price responsiveness to a price change by the competitor, and (ii) an augmented incentive for each player to increase its price. In this section, we provide a more detailed comparison of the two subsidy systems in terms of prices, output, profits, and welfare. We first compare the relative efficiency of the two systems in stimulating output with a given budget; next we proceed to a comparison of profits and welfare.

\subsection{Relative efficiency of the two subsidy systems}

Anderson et al. (2001) propose two ways to evaluate the efficiency of different taxes or subsidies. First, a subsidy instrument is more efficient than another if the former yields a higher output for a given subsidy budget. Second, a funding system is more efficient than another when 
it reaches the same output with a lower budget ${ }^{14}$. To fix ideas, we focus on the first definition. We comment on the second one at the end of this sub-section.

We compare the open-ended and closed-ended funding subsidy system by assuming that the government decides to move from a closed to an open system, while holding the total subsidy cost constant. Let the total cost of the subsidy under the initial closed system be $\beta$. Let us denote the per-unit subsidy that accomplishes an unchanged total subsidy cost in the open system as $\hat{\gamma}$. In other words, this per-unit subsidy must satisfy $\beta=2 \hat{\gamma} \hat{q}_{i}^{o}$, where $\hat{q}_{i}^{o}$ is the equilibrium quantity per firm that results from the per-unit subsidy $\hat{\gamma}$; by symmetry, we have $\hat{q}_{i}^{o}=\hat{q}_{j}^{o}$.

Using the equilibrium quantities under a per-unit subsidy system (see (9)) we have that:

$$
\beta=2 \hat{\gamma}\left[\frac{1+\hat{\gamma}}{(1+d)(2-d)}\right]
$$

Solving the resulting quadratic equation for $\hat{\gamma}$, we find that

$$
\hat{\gamma}=\frac{-1+\sqrt{1+2 \beta Z}}{2}
$$

where, as before, $Z \equiv(2-d)(1+d) .{ }^{15}$ From (8), this subsidy per unit implies a Nash equilibrium price of

$$
\hat{p}_{i}^{o^{*}}=\frac{1-\hat{\gamma}-d}{2-d}
$$

Substituting in (17) and working out yields

$$
\hat{p}_{i}^{o^{*}}=\frac{3-2 d-\sqrt{1+2 \beta Z}}{2(2-d)} .
$$

The equilibrium quantity demanded per firm is, substituting (17) in (9), equal to

$$
\hat{q}_{i}^{o^{*}}=\frac{1+\sqrt{1+2 \beta Z}}{2 Z} .
$$

Finally, simple algebra shows that profit per firm is, using (17), (18) and (19), equal to

$$
\hat{\pi}_{i}^{o^{*}}=\left(\hat{p}_{i}^{o^{*}}+\hat{\gamma}\right) \hat{q}_{i}^{o^{*}}=\frac{(1-d)[1+\sqrt{1+2 \beta Z}]^{2}}{4 Z(2-d)}
$$

\footnotetext{
${ }^{14}$ Anderson et al. (2001) show the two definitions are equivalent under mild conditions.

${ }^{15}$ The other root involves a per-unit tax yielding a tax revenue of $\beta$.
} 
Using the above results, we are now in a position to directly compare the two subsidy systems under the maintained assumption that the total subsidy cost to the government is equal. A comparison of (18) with the price under the initial closed system as in (14), shows that

$$
\hat{p}_{i}^{o^{*}}-p_{i}^{c^{*}}=\frac{\sqrt{1+\beta(1+d) Z}-\sqrt{1+2 \beta Z}}{2(2-d)}<0
$$

since $0<d<1$. Of course, comparing demands (see (19) and (15)) we find after simple algebra that $q_{i}^{c *}<\hat{q}_{i}^{o}$.

We have shown the following proposition.

Proposition 1: The efficiency of a given budget $\beta$ available for subsidies is higher for a per-unit subsidy than for a market-share based subsidy; the former results in fiercer price competition and a larger output than the latter.

When a given subsidy budget $\beta$ is available, there exists an appropriately chosen subsidy $\hat{\gamma}$ per unit in an open system that fully exhausts the available budget. This unit subsidy $\hat{\gamma}$ results in lower consumer prices and a higher output as compared to the closed-ended subsidy system. The intuition for this result is as follows. A price increase under the open subsidy system reduces a firm's demand and total demand, but it has no effect on the subsidy per unit. In a closed subsidy system, when firm $i$ changes its price, its demand changes in a similar fashion as under the openended system. However, it also raises the subsidy per unit for both players, since fewer units are sold. This change in the subsidy per unit explains why firms are less inclined to set a lower price in a closed-ended subsidy system as compared to the open-ended funding system. This results in a higher equilibrium price and, consequently, a lower total output.

Finally, following Anderson et al. (2001), in Appendix 1 we show a corollary to the result of this section, viz. that a smaller total subsidy is needed to generate the same output effect under an open per-unit subsidy than under a subsidy based on market shares. 


\subsection{Welfare comparison of open and closed budget subsidies}

In this subsection, we compare the welfare effects of the two subsidy systems, taking account of consumers' surplus, firms' profits, and the cost of the subsidy to the government. Since the social cost of government funding is, by assumption, equal for the closed and open subsidy system, we only consider the sum of the surpluses for consumers and firms.

As the open system implies lower prices, consumers will be better off. This is confirmed by calculating consumers' surplus. This is easily shown to equal

$$
C_{s}=(1+d) q^{2}
$$

for both subsidy systems, where $q$ is the output level per firm. Using (19) and (15), the difference in total consumer surplus on the market can, after simple algebra, be written as

$$
\hat{C}_{S}^{o^{*}}-C_{S}^{c^{*}}=\left[\frac{1-d}{4 Z^{2}}\right]\{2[\sqrt{1+2 \beta Z}-\sqrt{1+\beta(1+d) Z}]+\beta Z(1-d)\}
$$

This is necessarily positive, since $d<1$. Straightforward algebra shows that it increases in the size of the subsidy budget $\beta$.

Next, we compare profits under the open and closed system, holding subsidies constant. The profit difference per firm can be written as

$$
\hat{\pi}_{i}^{o^{*}}-\pi_{i}^{c^{*}}=\hat{p}_{i}^{o^{*}} \hat{q}_{i}^{o^{*}}-\hat{p}_{i}^{c^{*}} \hat{q}_{i}^{c^{*}} .
$$

Noting that $\beta=2 \hat{\gamma} \hat{q}_{i}^{o}$, using previous results and working out, we find that

$$
\hat{\pi}_{i}^{o^{*}}-\pi_{i}^{c^{*}}=\frac{(1-d)\{2[\sqrt{1+2 \beta Z}-\sqrt{1+\beta(1+d) Z}]-\beta Z\}}{4(2-d) Z}
$$

The profit difference tends to zero when goods become very close substitutes ( $d$ approaching 1 ) or when the subsidy is zero $(\beta=0)$. Moreover, in Appendix 2 we show that, for positive subsidies and $0 \leq d<1$, the profit difference (23) is necessarily negative. This result implies that the closed subsidy system yields higher profits for firms for all positive subsidy levels and less than perfect substitution between goods.

Finally, to compare total welfare (denoted $W$ ), let us define welfare as the sum of consumer surplus and sector profits (minus the cost of the subsidy to the government, which is equal by assumption). Taking into account that profits were calculated per firm, we find that

$$
\hat{W}^{o}-W^{c}=\frac{(1-d)}{4 Z^{2}}\{[\sqrt{1+2 \beta Z}-\sqrt{1+\beta(1+d) Z}][2(3+2 d)]-\beta Z(1+3 d)\} .
$$


The sign is ambiguous in general but depends on parameter values for $d, \beta$.

A simple numerical example will be instructive to understand the sensitivity of the results to parameter values. In Table 1 we report, for various combinations of $(d, \beta)$, equilibrium outcomes under the open and closed subsidy system. Specifically, we provide information on prices and quantities, and on the difference in total consumer surplus, total industry profit and overall welfare between the two systems.

The results of Table 1 suggest that the price difference between the open and closed system rises strongly in the total size of the subsidy. Although prices decline substantially when goods become better substitutes (larger $d$ ), the price difference between subsidy systems appears to be rather insensitive to variations in $d$. Consumers are always better off under the open system. The difference in consumer surplus rises in the subsidy but declines in $d$. For all parameter combinations considered, the closed system yields higher profit for firms; the profit advantage is more pronounced at higher subsidy levels and when goods are better substitutes. Finally, which system is best for overall welfare depends on parameter values: the open system performs better if both $d$ and $\beta$ are relatively small; however, large subsidies or high degrees of substitutability imply that welfare is higher for the closed system.

Summarizing our findings, we have shown that, moving from a closed to an open system, where the total budgetary cost is kept constant at the initial level under the closed system, leads to a lower price, more demand, and higher net consumer surplus. The unit subsidy is, therefore, more efficient in the sense of Anderson et al. (2001a,b): the same total subsidy yields more output. The open system is preferred by consumers, the closed system by producers. The effect on total welfare is ambiguous. We have the following proposition.

Proposition 2: For a given available budget for subsidies, consumers prefer the open-ended perunit price subsidy over the closed-ended system. Firms have higher profits under the open system. In terms of overall welfare, the open system performs better for low subsidies and when goods are relatively poor substitutes, the closed system generates more welfare for large subsidies and close substitutes.

Our results suggest that if there is a fixed government budget, and the social concern for consumer participation or output is the most important objective, the open-ended system with a 
per-unit subsidy is to be favored. An important example may include the public promotion of educational participation programs. ${ }^{16}$ If, however, the main concern is to convince firms to participate, the closed system seems to be most effective as this generates the highest increase in producer surplus. For example, suppose the government wants to introduce higher, and more costly production standards that favor product safety or reduce the impact on the environment. Producers will be more willing to invest in costly effort under a closed-ended (market-share based) subsidy system if their marginal profits increase more. ${ }^{17}$

\begin{tabular}{l|llllllll}
$\boldsymbol{d}$ & $\beta$ & $\hat{p}_{i}^{o^{*}}$ & $\hat{q}_{i}^{o}$ & $p_{i}^{c^{*}}$ & $q_{i}^{c^{*}}$ & $\hat{C}_{S}^{o^{*}}-C_{S}^{c^{*}}$ & $\hat{\pi}_{i}^{o^{*}}-\pi_{i}^{c^{*}}$ & $\hat{W}^{o}-W^{c}$ \\
\hline $\mathbf{0}$ & $\mathbf{0}$ & 0.500 & 0.500 & 0.500 & 0.500 & 0 & 0 & 0 \\
\hline $\mathbf{0}$ & $\mathbf{0 . 1}$ & 0.454 & 0.546 & 0.476 & 0.524 & 0.023 & -0.003 & 0.020 \\
& $\mathbf{0 . 3}$ & 0.379 & 0.621 & 0.433 & 0.566 & 0.065 & -0.02 & 0.044 \\
& $\mathbf{0 . 5}$ & 0.317 & 0.683 & 0.396 & 0.604 & 0.102 & -0.046 & 0.057 \\
\hline & & & & & & & & \\
\hline $\mathbf{0 . 1}$ & $\mathbf{0 . 1}$ & 0.423 & 0.524 & 0.445 & 0.505 & 0.0181 & -0.005 & 0.013 \\
\hline & $\mathbf{0 . 3}$ & 0.342 & 0.589 & 0.395 & 0.55 & 0.050 & -0.025 & 0.024 \\
\hline & $\mathbf{0 . 5}$ & 0.274 & 0.660 & 0.375 & 0.590 & 0.078 & -0.052 & -0.116 \\
\hline & & & & & & & & \\
\hline $\mathbf{0 . 5}$ & $\mathbf{0 . 1}$ & 0.265 & 0.489 & 0.281 & 0.480 & 0.005 & -0.009 & -0.004 \\
\hline & $\mathbf{0 . 3}$ & 0.156 & 0.563 & 0.194 & 0.537 & 0.014 & -0.033 & -0.019 \\
\hline & $\mathbf{0 . 5}$ & 0.066 & 0.623 & 0.120 & 0.587 & 0.022 & -0.059 & -0.037 \\
\hline $\mathbf{0 . 9}$ & $\mathbf{0 . 1}$ & 0.004 & 0.524 & 0.008 & 0.522 & 0.000 & -0.004 & -0.004 \\
\hline & $\mathbf{0 . 3}$ & $<0$ & & $<0$ & & & & \\
\hline & $\mathbf{0 . 5}$ & $<0$ & & $<0$ & & & & \\
\hline
\end{tabular}

Table 1: numerical welfare comparison between the open and closed subsidy system.

\footnotetext{
${ }^{16}$ Clearly, if participation is of so much importance, a government may find it optimal to impose mandatory participation, like it very often does for primary and secondary education. In that event, our two alternative subsidy systems coincide. Any compulsory participation would, by construction, result in identical participation and have no effect on the market size. For example, in a simple Hotelling model with two firms at opposing ends of the unit interval, either firm would attract half of the fixed number of consumers under both subsidy systems. With identical budget availability, this results in identical prices. Our set-up, therefore, is only relevant when no mandatory participation is imposed, like is the case for higher education.

${ }^{17}$ Suppose the increased environmental-friendly production standard requires a fixed expenditure of $F^{e}$. Firms are only willing to introduce this new standard under the closed-ended (market-share based) system whenever $\hat{\pi}_{i}^{o^{*}}(\hat{\gamma})-\hat{\pi}_{i}^{o^{*}}(0)<F_{e}<\pi_{i}^{c^{*}}(\beta)-\pi_{i}^{c^{*}}(0)$.
} 


\section{Subsidy systems and potential collusion}

The previous section focused on the welfare effects of different types of subsidies to competing firms. In this section, we study a different question that relates to long-run differences in industry behavior. Specifically, we compare firms' incentives to collude under the two subsidy systems. This is relevant, because short-run advantages of a particular system may have to be traded-off against potential long-run and undesirable implications on industry conduct.

To find out under what subsidy system collusion is more likely, we assume firms make use of grim trigger strategies. Each firm compares the discounted stream of its profits under collusion with its profits from deviating (in the sense of undercutting its rival, who is assumed to stick to the collusive price), plus all future profits if the rival retaliates. The game reverts to the static Nash equilibrium outcome for all future periods after one of the players deviated from the collusive outcome. Assuming a common discount factor $0<\delta<1$, collusion is beneficial to an arbitrary firm whenever ${ }^{18}$

$$
\frac{\pi^{\text {coll }}}{1-\delta} \geq \pi^{\text {dev }}+\frac{\delta}{1-\delta} \pi^{N E}
$$

where $\pi^{\text {coll }}, \pi^{d e v}, \pi^{N E}$ are, respectively (i) each firm's profits when all firms respect the collusive arrangement (i.e. $\pi^{\text {coll }}$ is half the industry monopoly), (ii) the profits when the firm deviates and undercuts its rival, and (iii) the profits in the Nash equilibrium. Rearranging, we have that the condition

$$
\delta \geq \frac{\pi^{d e v}-\pi^{\text {coll }}}{\pi^{d e v}-\pi^{N E}}
$$

is sufficient for collusion to arise. We now study how subsidies affect the condition for collusion.

\subsection{Open subsidy system}

When both firms collude under the open system, the profit maximization problem reduces to

$$
\operatorname{Max}_{p^{o}} \quad 2\left(p^{o}+\gamma\right) \frac{1}{1-d^{2}}\left[(1-d)-p^{o}+d p^{o}\right]
$$

\footnotetext{
${ }^{18}$ In this section, we have deleted firm-specific subscripts in order not to overburden notation.
} 
The collusive price and quantity per firm are easily shown to be

$$
p_{\text {coll }}^{o}=\frac{1-\gamma}{2} \text { and } q_{\text {coll }}^{o}=\frac{1+\gamma}{2(1+d)} .
$$

Substituting and working out shows that the total collusive profit per firm equals

$$
\pi_{\text {coll }}^{o}=\frac{(1+\gamma)^{2}}{4(1+d)} \text {. }
$$

When a firm deviates from the collusive agreement and undercuts its rival, it solves

$$
\operatorname{Max}_{p_{\text {dev }}^{o}} \pi=\left(p_{d e v}^{o}+\gamma\right) \frac{1}{1-d^{2}}\left[(1-d)-p_{d e v}^{o}+d p_{c o l l}^{o}\right]
$$

where the rival firm charges the collusively agreed price $p_{\text {coll }}^{o}$. The optimal price is given by

$$
p_{d e v}^{o}=\frac{2(1-\gamma)-(1+\gamma) d}{4}
$$

wherefrom profits can be written as

$$
\pi_{d e v}^{o}=\frac{[(1+\gamma)(2-d)]^{2}}{16\left(1-d^{2}\right)} .
$$

Finally, Nash equilibrium profit reads

$$
\pi_{N E}^{o}=\frac{(1-d)(1+\gamma)^{2}}{(1+d)(2-d)^{2}} .
$$

We want to find out how an increase in the subsidy $\gamma$ affects the condition

$$
\delta \geq \frac{\pi_{d e v}^{o}-\pi_{c o l l}^{o}}{\pi_{d e v}^{o}-\pi_{N E}^{o}}
$$

for collusion. Substitution of (26), (27) and (28) in the inequality for the discount rate immediately shows that the critical discount factor only hinges on the degree of product differentiation $d$ and is independent of $\gamma$. With hindsight, this is no surprise, as the subsidy acts like a profit-increasing reduction in the constant marginal cost for both firms. ${ }^{19}$ An open subsidy system has, therefore, no effect on the likelihood of collusive arrangements among firms.

\footnotetext{
19 To see why incentives to collude are independent of $\gamma$, note that our model implies that $\pi_{d e v}^{o} \equiv \rho \pi_{\text {coll }}^{o}$ and $\pi_{N E}^{o} \equiv \sigma \pi_{\text {coll }}^{o}$, where $\rho$ and $\sigma$ are independent of the unit subsidy, and $0 \leq \sigma \leq 1 \leq \rho$. Since marginal costs are constant, the critical $\delta$ is independent of the unit subsidy.
} 


\subsection{Closed subsidy system}

The total government budget is fixed and denoted by $\beta$. Each firm gets a fraction of the budget according to its market share. To see whether the subsidy system affects the likelihood of collusive actions being undertaken, we follow the same logic as before.

When the firms collude, the profit maximization problem for an arbitrary firm reduces to

$$
\operatorname{Max}_{p} 2 p q(p)=\frac{2 p}{1-d^{2}}[(1-d)-p+d p]+\beta .
$$

The optimal price and profit (for each firm) are denoted as

$$
p_{\text {coll }}^{c}=\frac{1}{2} \text { and } \pi_{\text {coll }}^{c}=\frac{1}{4}+\frac{\beta}{2},
$$

respectively. Clearly, as with monopoly, the price is now independent of the subsidy, which has a lump sum character when the firms collude.

Denote by $\pi_{N E}^{c}$ the Nash equilibrium profit, and let $\pi_{d e v}^{c}$ be the profit a firm receives when it optimally deviates from the collusive price. To find out how the subsidy $\beta$ affects the condition

$$
\delta \geq \frac{\pi_{d e v}^{c}-\pi_{c o l l}^{c}}{\pi_{d e v}^{c}-\pi_{N E}^{c}} \equiv T
$$

we differentiate the right hand side (which we have denoted T) with respect to $\beta$ and evaluate the result. The derivative can be written as

$$
\frac{\partial T}{\partial \beta}=\left[\frac{1}{\pi_{d e v}^{c}-\pi_{N E}^{c}}\right]^{2}\left\{\left(\pi_{d e v}^{c}-\pi_{N E}^{c}\right)\left(\frac{\partial \pi_{d e v}^{c}}{\partial \beta}-\frac{\partial \pi_{c o l l}^{c}}{\partial \beta}\right)-\left(\pi_{d e v}^{c}-\pi_{c o l l}^{c}\right)\left(\frac{\partial \pi_{d e v}^{c}}{\partial \beta}-\frac{\partial \pi_{N E}^{c}}{\partial \beta}\right)\right\}
$$

Note that we do not have an explicit solution in the event firm $i$ deviates from the collusive price. However, we are only interested in the sign of $\frac{\partial T}{\partial \beta}$. To analyze this sign, we first show the following results

$$
\frac{\partial \pi_{\text {coll }}^{c}}{\partial \beta}=0.5 ; \quad \frac{\partial \pi_{d e v}^{c}}{\partial \beta}=\frac{q_{d e v}^{c}}{q_{d e v}^{c}+q_{\text {coll }}}>0.5 ; \quad \frac{\partial \pi_{N E}^{c}}{\partial \beta}=0.5 .
$$

The first expression follows from differentiating (29). The second and the third are obtained by noting that

$$
\frac{\partial \pi_{k}^{c}}{\partial \beta}=\left.\frac{\partial \pi_{k}^{c}}{\partial \beta}\right|_{p_{k}^{c}}+\frac{\partial \pi_{k}^{c}}{\partial p_{k}^{c}} \frac{\partial p_{k}^{c}}{\partial \beta} \quad \text { with } k=\operatorname{dev}, N E
$$


The first term on the right hand side coincides with the market share, and the second term on the right hand side equals zero by the first-order condition for profit maximizing behavior.

Substituting the derivatives (31) into (30), it easily follows that

$$
\frac{\partial T}{\partial \beta}=\left[\frac{1}{\pi_{\text {dec }}^{c}-\pi_{N E}^{c}}\right]^{2}\left\{\left(\frac{q_{\text {dev }}^{c}}{q_{\text {dev }}^{c}+q_{\text {coll }}^{c}}-\frac{1}{2}\right)\left(\pi_{\text {coll }}^{c}-\pi_{N E}^{c}\right)\right\} .
$$

Since the deviating firm has a market share exceeding $50 \%$ and collusion yields higher profit than the Nash equilibrium, it follows that

$$
\frac{\partial T}{\partial \beta}>0
$$

for all $\beta>0$. Put differently, the cut-off discount rate that makes collusion profitable is increasing in the amount available for subsidizing the sector. Of course, in the special case without subsidies ( $\beta=0$ ), all results for open and closed system are identical. As the incentives to collude do not depend on the size of the subsidy for the open system but do rise in the available subsidy under the closed system, we can conclude that a closed system implies less incentive to collude. We have the following proposition.

Proposition 3: The incentives to collude augment under a closed-ended market-share based funding system when the subsidy increases. On the contrary, in an open subsidy system variations in the per-unit subsidy do not affect incentives to collude. The closed system makes collusion harder as compared to the open system.

The intuition for this result is easy to grasp. Observe that the collusive price is independent of the total subsidy $\beta$. As a result, an increase in $\beta$ does not result in a positive total market effect so that each firm's demand remains constant as well. Consequently, more subsidies necessarily lead to an increase in profit by $0.5 \Delta \beta$ for both firms. However, when a firm deviates, the deviating firm reduces its price so that its market share rises above one half. 
An increase in the total subsidy therefore makes deviating behavior relatively more attractive as compared to collusion. Hence, larger subsidies reduce the incentives for collusion.

Our result suggests that raising the subsidy in a closed subsidy system reduces the potential for collusive behavior. If we take the zero subsidy case as starting point (or consider a move from an open to a closed system whereby the subsidy rises) then this suggests that a closed system hampers the potential for collusion. Alternatively, we showed before that a closed system (holding demand constant) raises the total subsidy cost compared to an open system, hence there is less potential for collusion in a closed system. A potential trade off exists, therefore, in the sense that under a closed system the consumer loses (a short-term loss), but at consumers' benefit of less incentives for firms to collude (a long-run benefit).

\section{Conclusions}

Governments often offer subsidies to competing firms or organizations. Prominent examples can be found in, among others, the arts and the education industry. This paper has studied the implications of different, commonly observed subsidy systems on the strategic behavior of firms in the industry. We analyzed a stylized model with two price-competing, subsidized firms offering a differentiated product. Two existing subsidy systems were considered. In the open-ended system, the government provides a per unit subsidy that is known by firms ex ante. In the alternative closed-ended system, a fixed subsidy is available for the sector as a whole, and the allocation rule is based on firms' market shares in industry output.

We have shown that, holding the total subsidy budget constant, a per-unit subsidy results in fiercer price competition than a market-share based subsidy. As a result, it generates a larger market output and, therefore, it is more effective at stimulating wider participation. Firms' profits, however, are higher under the closed system. Welfare is higher under the open system provided goods are not too close substitutes and subsidy levels are relatively low. For large subsidies, the closed system outperforms the open system in terms of welfare. Finally, a marketshare based subsidy makes collusive behavior between firms more difficult than an open per unit subsidy. Our results, therefore, may imply a potential trade-off between short-run and long-run objectives of governments. For example, subsidy systems that are better suited to stimulate participation may also provide more incentives for firms to collude. 
Our model was deliberately simple, and a number of extensions can be thought of. First, the specification of consumer utility was quite restrictive. Although it highlighted the role of substitutability between goods in a highly transparent way, more realistic specifications might provide additional information on, for example, the role of explicit differences in preferences for one of the goods (for example, consumers may have intrinsic preferences in favor of a particular theatre or university). Second, the model could be extended to an oligopolistic market structure with more than two firms; however, this exercise is unlikely to affect the main insights. Third, it has been argued above that organizations may compete in quality as well as price. Incorporating quality competition seems a useful extension, although initial efforts along these lines suggest that transparent analytical results may be hard to derive. Fourth, alternative objective functions could be conceived. Finally, our model implies that, when firms strategically interact, designing open versus closed-ended subsidy schemes matters for both consumers and producers. A useful extension would be to incorporate subsidy schemes in a more elaborate political economy model in which all interest groups lobby for one or the other subsidy system. This might explain the variety of different systems observed in practice. 


\section{References}

Anderson, S., de Palma, A. and B. Kreider, 2001a, Tax incidence in a differentiated product oligopoly, Journal of Public Economics, 81, 173-192.

Anderson, S. , de Palma, A. and B. Kreider, 2001b, The efficiency of indirect taxes under imperfect competition, Journal of Public Economics, 81, 231-251.

Barr, N., Higher education funding, 2004, Oxford Review of Economic Policy, 20, 2, 264-283.

Bok, D., 2004, Universities in the marketplace: the commercialization of higher education, Princeton University Press.

Clarke, R. and D.R. Collie, 2003, Product differentiation and the gains from trade under Bertrand duopoly, Canadian Journal of Economics 36, 658-673.

Collie, D.R., 2000, State aid in the European Union: The prohibition of subsidies in an integrated market, International Journal of Industrial Organization, 18, 867-884.

Deneckere, R., 1983, Duopoly supergames with product differentiation, Economics Letters, 11, 37-42.

Fethke, G., 2005, Strategic determination of higher education subsidies and tuitions, Economics of Education Review, 24, 601-9.

Fethke, G. 2006, Subsidy and tuition policies in public higher education, Economic Inquiry, 44, 4, 644-55.

Fischer, C., 2003, Market power and output-based refunding of environmental policy revenues, Resources for the Future, Discussion Paper 03-27. 
Fuest, C. and P. Tillessen, 2005, Why do governments use closed ended subsidies to support entrepreneurial investment, Economics Letters 89, 24-30.

Hansmann, H., 1981, Nonprofit enterprise in the performing arts, Bell Journal of Economics, Vol. 12, 2, Autumn, 341-361.

Heckman, J. , 2000, Policies to foster human captial, Research in Labour Economics, 54, 3-56.

HEFCA, Funding higher education in England, Higher Education Funding Council for England, 2008.

Jacobs, B. and R. Van der Ploeg, 2006, Guide to reform of higher education: A European perspective, Economic Policy 47, 535-592.

Krishna, K., Suddhasatwa, R., and M. Thursby, 2001, Can subsidies for MARs be procompetitive? , Canadian Journal of Economics, 34, 1, 212-224.

Santiago, P., Tremblay, K., Basri, E. and E. Arnal, 2008, Tertiary education for the knowledge Society, Volume 1, OECD.

Kalpazidou, P., Schmidt, E., Langberg, K., and K. Aagaard, 2007, Funding Systems and their Effects on Higher Education Systems. Country Report Denmark, in Strehl, F., Reisinger, S., Kalatschan, M. (red.) Funding Systems and their Effects on Higher Education Systems, OECD, Paris.

Segal, I.R., Monopoly and soft budget constraint, RAND Journal of Economics, 29, 3, 596-609.

Sen, A.K., 1966, Labour allocation in a cooperative enterprise, Review of Economic Studies 33, 361-371. 
Singh, N. and X. Vives, 1984, Price and quantity competition in a differentiated duopoly, RAND Journal of Economics, 15, 4, Winter, 546-554.

Szymanski, S., 2003, The economic design of sporting contests, Journal of Economic Literature, Vol. XLI, December, 1137-87.

Vives, X., 1985, On the efficiency of Bertrand and Cournot equilibria with product differentiation, Journal of Economic Theory, 36, 166-75

Winston, G., 1999, Subsidies, hierarchies and peers: The awkward education of higher education, Journal of Economic Perspectives 13, 13-36.

Winston G.C. and D.J. Zimmerman, 2000, Where Is Aggressive Price Competition Taking Higher Education? Change, Vol. 32, 4, 10-19. 


\section{Appendix 1}

In this appendix we consider, for completeness sake, a move from a closed to an open system in which the user price (and hence demand) is kept constant. As we focus on symmetric solutions, we delete firm-specific subscripts. Denote the subsidy, the price and demand after the move to the open system as $\bar{\gamma}, \bar{p}, \bar{Q}$, respectively. We then require:

$$
\bar{p}=p^{*}->\frac{1-\bar{\gamma}}{2-d}=\frac{(3-2 d)-\sqrt{1+(1+d) Z}}{2(2-d)(1-d)}
$$

Solving leads to

$$
\bar{\gamma}=\frac{-1+\sqrt{1+(1+d) Z}}{2(1-d)}
$$

This unit subsidy implies the same price and the same demand $\left(\bar{p}=p^{*}, \bar{Q}=Q^{*}\right.$, respectively) that we had under the closed system. However, it implies a lower budgetary cost to the government. To see this, note that the total $\operatorname{cost}$ is $2 \bar{\gamma} \bar{Q}$. Using (A2) and (9) we find:

$$
2 \bar{\gamma} \bar{Q}=\frac{(1+d) Z}{2(2-d)(1-d)}
$$

Using the definition of $Z$, we have

$$
2 \bar{\gamma} \bar{Q}=\frac{\beta(1+d)}{2}
$$

Since $d<1$ we have that $2 \bar{\gamma} \bar{Q}<\beta$.

Hence, the unit subsidy is more efficient in the sense of Anderson et al (2001). This is just a collorary of the result we showed above (higher output and hence consumer surplus for given subsidy cost). The intuition is clear. The unit subsidy is more efficient in stimulating demand, so that a smaller subsidy is needed to generate the same demand effect as the subsidy according to market share. Note that, using (17) and (A2), we also see that $\hat{\gamma}>\bar{\gamma}$.

\section{Appendix 2}

In this appendix, we show that the closed system necessarily yields higher profits for firms for all positive subsidies and $0 \leq d<1$. To see this, differentiate (23) with respect to $\beta$ to find: 


$$
\frac{\partial\left(\hat{\pi}_{i}^{o^{*}}-\pi_{i}^{c^{*}}\right)}{\partial \beta}=\left[\frac{1-d}{4(2-d)}\right]\left[\frac{2}{\sqrt{1+2 \beta Z}}-\frac{(1+d)}{\sqrt{1+\beta(1+d) Z}}-1\right]
$$

The sign of the final term between brackets on the right-hand side is the same as the sign of

$$
[2 \sqrt{1+\beta(1+d) Z}-(1+d) \sqrt{1+2 \beta Z}-(\sqrt{1+\beta(1+d) Z})(\sqrt{1+2 \beta Z})]
$$

Reformulation gives

$$
[\sqrt{1+\beta(1+d) Z}-\sqrt{1+2 \beta Z}]+[\sqrt{1+\beta(1+d) Z}(1-\sqrt{1+2 \beta Z})]-[d \sqrt{1+2 \beta Z}]
$$

This is necessarily negative, given $d<1$. Therefore, raising the subsidy necessarily reduces the right-hand side of (23). As the profit difference is zero at zero subsidies this implies that the closed subsidy system yields higher profits for firms for all positive subsidies and less than perfect substitution between goods. 